\title{
Tétano em bovinos no sul do Rio Grande do Sul: estudo de 24 surtos $^{1}$
}

\author{
Pedro S. Quevedo ${ }^{2}$, Silvia R. L. Ladeira ${ }^{3}$, Mauro P. Soares ${ }^{3}$, Clairton Marcolongo-Pereira ${ }^{2}$, \\ Elisa S. V. Sallis ${ }^{4}$, Fabiane B. Grecco ${ }^{4}$, Pablo Estima-Silva ${ }^{5}$ e Ana Lucia Schild ${ }^{3 *}$
}

\begin{abstract}
Quevedo P.S, Ladeira S.R.L., Soares M.P., Marcolongo-Pereira C., Sallis E.S.V., Grecco F.B., Estima-Silva P. \& Schild A.L. 2011. [Tetanus in cattle in southern Brazil: study of 24 outbreaks.] Tétano em bovinos no sul do Rio Grande do sul: estudo de 24 surtos. Pesquisa Veterinária Brasileira 31(12):1066-1070. Laboratório Regional de Diagnóstico, Faculdade de Veterinária, Universidade Federal de Pelotas, Campus Universitário s/n, Pelotas, RS 96010-900, Brazil. E-mail: alschild@terra.com.br

Twenty-four outbreaks of tetanus occurred in 2009 in beef cattle on farms located in the region of influence of the Regional Diagnostic Laboratory (LRD), southern Rio Grande de Sul, are described. All herds were submitted to vaccination and/or application of anthelmintics between 8 and 25 days before the onset of clinical signs of tetanus. Those were prolapse of the third eyelid, stiff gait, recumbency with limbs extended and off the ground (spastic paralysis), very open eyelids, salivation, hyperexcitability, erect ears, mandibular trismus, food accumulation in the oral cavity, and presence of foam in mouth and nostrils in some cases. At postmortem some animals had necrosis, edema and hemorrhage surrounded by purulent exudate in the muscles where some medicine had been applied. Blood serum and muscle fragments of affected animals were collected for subsequent inoculation into mice. No changes were evident in histological examination. The clinical and epidemiological data associated with the absence of histological lesions allowed the diagnosis of tetanus. The infection probably occurred during the vaccination procedure, by intramuscular injections using contaminated needles. Although tetanus is not an important disease in the region, outbreaks could occur depending on epidemiological conditions. Appropriate care should be taken to avoid major economic losses as those that occurred in 2009 in the region.
\end{abstract}

INDEX TERMS: Tetanus, Clostridium tetani, cattle.

RESUMO.- São descritos vinte e quatro surtos de tétano ocorridos no ano 2009 em bovinos de corte em propriedades situadas na região de influência do Laboratório Regional de Diagnóstico (LRD), sul do Rio Grande de Sul. Todos os rebanhos foram submetidos a procedimentos de vacinação e/ou aplicação de anti-helmíntico entre 8 e 25 dias antes do aparecimento dos primeiros sinais clínicos. 0 tempo de

${ }^{1}$ Recebido em 19 de junho de 2011.

Aceito para publicação em 2 de setembro de 2011

${ }^{2}$ Alunos do Programa de Pós-Graduação em Medicina Veterinária, Faculdade de Veterinária, Universidade Federal de Pelotas (UFPel), Campus Universitário s/n, Pelotas, RS 96010-900, Brasil.

${ }^{3}$ Laboratório Regional de Diagnóstico, Faculdade de Veterinária, UFPel, Pelotas, RS.*Autor para correspondência: alschild@terra.com.br

${ }^{4}$ Professoras Adjuntas do Departamento de Patologia Animal, FV-UFPel, Pelotas, RS.

${ }^{5}$ Aluno do Curso de Graduação em Medicina Veterinária, Bolsista de IC-CNPq evolução variou de 12 horas até quatro dias. Os sinais clínicos observados foram: prolapso da terceira pálpebra, andar rígido, dificuldade de flexão dos membros e permanência em decúbito lateral com os membros estendidos e afastados do solo (paralisia espástica), pálpebras muito abertas, sialorréia, hiperexcitabilidade, orelhas eretas, trismo mandibular, acúmulo de alimento na cavidade oral e presença de espuma na boca e narinas em alguns casos. Alguns bovinos apresentavam área de necrose e edema hemorrágico circundada por exsudato purulento nos músculos onde havia sido aplicado algum medicamento. 0 soro sanguíneo e fragmentos de músculo com lesão de animais afetados foram coletados para posterior inoculação em camundongos. No exame histopatológico não foram evidenciadas alterações. 0 quadro clínico associado aos dados epidemiológicos e a ausência de lesões histológicas permitiram o diagnóstico de tétano. A infecção, provavelmente ocorreu durante o procedimento de vacinação, através injeções in- 
tramusculares utilizando agulhas contaminadas. Apesar do tétano não ser uma clostridiose importante na região fica evidenciado que surtos podem ocorrer em função de condições epidemiológicas adequadas e cuidados devem ser tomados para evitar perdas econômicas importantes como as que ocorreram no ano 2009 na região.

TERMOS DE INDEXAÇÃO: Tétano, Clostridium tetani, bovinos.

\section{INTRODUÇÃO}

Tétano é uma doença infecciosa não contagiosa de etiologia conhecida desde o século XIX, quando foi experimentalmente reproduzida (Saraiva et al. 1984). É altamente letal e acomete todos os mamíferos (Lobato \& Assis 2005, Lobato et al. 2007), porém os eqüinos são mais sensíveis (Lobato \& Assis 2005). Em ovinos o tétano é mais freqüente que em bovinos, ocorrendo em consequência da castração ou por feridas de tosquia (Riet-Correa et al. 1998). Clostridium tetani é comumente encontrado em solos contaminados por fezes (Tortora 2000). É um bacilo Gram-positivo, anaeróbico estrito e formador de esporos terminais que variam de arredondados a ovais (Saraiva et al. 1984, Carter et al. 1995).

A patogenia da doença envolve a penetração de esporos de Clostridium tetani (Lobato \& Assis 2005) em feridas, com consequente multiplicação e produção de uma potente neurotoxina, a tetanospasmina (Lobato et al. 2007). Para a manifestação clínica do tétano é necessário ferimento ou solução de continuidade que possibilite a introdução da bactéria (Barros et al. 2006).

0 clostrídio, em anaerobiose, produz três exotoxinas conhecidas: toxina não espasmogênica, tetanolisina, que promove necrose tissular, e tetanoespasmina que produz os sinais clínicos do tétano (Barros et al. 2006). A tetanoespasmina liga-se às terminações nervosas e segue em fluxo retrógrado do sistema nervoso periférico (local do ferimento) ao sistema nervoso central (Raposo 2007). A toxina chega ao interior de neurônios inibidores, impedindo a liberação dos neurotransmissores: ácido gama amino butírico (GABA) e glicina (Barros et al. 2006). A capacidade de inibir informações indesejáveis que partem do sistema nervoso rumo à musculatura é perdida. Devido esta falta de inibição dos neurônios motores ocorre rigidez muscular (tetania) (Barros et al. 2006). 0 período de incubação varia de 7 a 21 dias para a maioria das espécies susceptíveis (Tortora 2000). Em bovinos, no entanto, o período de incubação pode variar de 18 horas a quatro semanas (Barros et al. 2006). Os sinais clínicos iniciam em geral em 7 a 15 dias após a infecção do animal (Barros et al. 2006). Trismo mandibular, marcha trôpega, prolapso de terceira pálpebra, orelhas eretas, timpanismo e rigidez dos membros são comumente manifestados (Barbosa et al. 2009). A necropsia não revela lesões macroscópicas, exceto eventuais áreas de necrose no local onde o clostrídio teve condições de multiplicar-se (Barbosa et al. 2009). Não existem lesões histológicas específicas da doença (Barros et al. 2006). A ocorrência desta enfermidade em geral é esporádica, mas surtos têm ocorrido em bovinos após práticas zootécnicas como, por exemplo, aplicação de vermífugos ou vacinas com o uso de equipamentos não higienizados devidamente ou através da contaminação da pele por poeira ou lama durante tais práticas (Dutra et al. 2001).

$\mathrm{Na}$ área de influência do Laboratório Regional de Diagnóstico da Faculdade de Veterinária da Universidade Federal de Pelotas (LRD/UFPel) entre 1978 e 2008 foram observados apenas três surtos de tétano considerando-se uma clostridiose pouco importante para bovinos na região (Schild et al. 2008).

Os objetivos do presente trabalho foram descrever 24 surtos de tétano diagnosticados em bovinos na região sul do Rio Grande do Sul no ano 2009 e discutir alguns aspectos epidemiológicos que favoreceram a ocorrência dos mesmos.

\section{MATERIAL E MÉTODOS}

Foram estudados 24 surtos de tétano ocorridos entre abril e dezembro de 2009 em 24 propriedades de 11 municípios na área de influência do Laboratório Regional de Diagnóstico (LRD) da Universidade Federal de Pelotas (UFPel). Os dados epidemiológicos e os sinais clínicos foram obtidos através de visitas às propriedades com casos de tétano e pela observação dos animais acometidos.

Foram necropsiados 24 bovinos mortos ou eutanasiados in extremis. Antes da eutanásia era realizada a coleta de sangue para obtenção de soro. Fragmentos de órgãos das cavidades abdominal e torácica e sistema nervoso central foram coletados, fixados em formalina a $10 \%$, processados pelos métodos rotineiros, cortados com $5 \mu \mathrm{m}$ de espessura e corados com hematoxilina-eosina (HE).

Áreas de necrose muscular foram coletadas, mantidas sob refrigeração e encaminhadas ao laboratório de bacteriologia do LRD. Esfregaços dessas lesões foram corados pelo método de Gram. Este material foi semeado em meio de Robertson incubado a $37^{\circ} \mathrm{C}$ por 48 horas para produção de toxina e inoculação em camundongos. Foram utilizados 48 camundongos divididos em 12 grupos de quatro, os quais foram inoculados com soro sanguíneo de bovinos doentes provenientes de 12 surtos da enfermidade. Dois camundongos de cada grupo eram protegidos com $0,5 \mathrm{ml}$ de soro antitetânico com título em torno de 100 a $200 \mathrm{UI} /$ $\mathrm{ml} 2$ horas antes da inoculação (Saraiva et al. 1984, Carter et al. 1995). Outros 24 camundongos foram inoculados com $0,2-0,5 \mathrm{ml}$ do sobrenadante do meio de Robertson, sendo que 12 foram protegidos com soro antitetânico nas mesmas condições descritas anteriormente. Outros 24 camundongos foram inoculados com o exsudado coletado nas lesões musculares de bovinos acometidos utilizando a mesma metodologia de proteção em metade dos animais. Os camundongos ficaram aos pares em caixas com ração, água e cama de serragem.

\section{RESULTADOS}

Nos 24 surtos de tétano diagnosticados no ano 2009, morreram 242 bovinos de um total de 14.745 animais em 11 municípios da área de influência do LRD. A morbidade variou de $0,2 \%$ a $39,4 \%$ e a letalidade de $88,8 \%$ a $100 \%$. Os dados epidemiológicos dos 24 surtos são apresentados no Quadro 1.

Em todos os casos foi mencionada a aplicação de vacinas ou vermífugos nos bovinos entre 8 e 25 dias antes do início das manifestações clínicas da enfermidade. Em todos os surtos os animais afetados apresentavam rigidez muscular, 
Quadro 1. Epidemiologia e clínicos dos surtos de tétano diagnosticados em bovinos no sul do Rio Grande do Sul no ano 2009

\begin{tabular}{|c|c|c|c|c|c|c|c|}
\hline Surto & Município & Mês/Ano & Idade & $\begin{array}{l}\text { Animais } \\
\text { sob risco }\end{array}$ & $\begin{array}{c}\text { Morbidade } \\
(\%)\end{array}$ & $\begin{array}{c}\text { Mortalidade } \\
(\%)\end{array}$ & Sinais clínicos \\
\hline 1 & São Lourenço do Sul & $04 / 2009$ & 1,5 anos & 3000 & $19(0,63)$ & $17(0,57)$ & $\begin{array}{l}\text { Andar rígido, decúbito } \\
\text { com opistótono, prola- } \\
\text { pso de } 3^{a} \text { pálpebra }\end{array}$ \\
\hline 2 & Turuçu & $04 / 2009$ & 1,5 anos & 1400 & $10(0,71)$ & $10(0,71)$ & Andar rígido, tetania \\
\hline 3 & Cristal & $05 / 2009$ & 8 meses & 352 & $17(4,82)$ & $17(4,82)$ & Andar rígido, tetania \\
\hline 4 & Morro Redondo & $05 / 2009$ & 1,5 anos & 50 & $7(14,0)$ & $7(14,0)$ & Andar rígido, tetania \\
\hline 5 & Pelotas & $05 / 2009$ & Adulto & 380 & $22(5,78)$ & $22(5,78)$ & Andar rígido, tetania \\
\hline 6 & Cristal & $05 / 2009$ & Variada & 350 & $17(4,85)$ & $17(4,85)$ & Andar rígido, tetania \\
\hline 7 & Dom Pedrito & $05 / 2009$ & Adulto & 720 & $9(1,25)$ & $9(1,25)$ & Andar rígido, tetania \\
\hline 8 & Capão do Leão & $05 / 2009$ & Adulto & 248 & $27(10,88)$ & $24(9,67)$ & $\begin{array}{l}\text { Andar rígido, timpanis- } \\
\text { mo e opistótono }\end{array}$ \\
\hline 9 & São Lourenço do Sul & $06 / 2009$ & Variada & 225 & $16(7,11)$ & $16(7,11)$ & Andar rígido, tetania \\
\hline 10 & Cristal & $06 / 2009$ & Adultos & 561 & $14(2,49)$ & $14(2,49)$ & Andar rígido, tetania \\
\hline 11 & Rio Grande & $06 / 2009$ & 4 meses a 3 anos & 1000 & $7(0,7)$ & $7(0,7)$ & Andar rígido, tetania \\
\hline 12 & Santa Vitória & $06 / 2009$ & 2 anos & 800 & $6(0,75)$ & $6(0,75)$ & Andar rígido, tetania \\
\hline 13 & São Lourenço do Sul & $07 / 2009$ & 2,5 a 3 anos & 1000 & $2(0,2)$ & $2(0,2)$ & Andar rígido, tetania \\
\hline 14 & Dom Pedrito & $07 / 2009$ & 1,5 anos & 84 & $7(8,3)$ & $7(8,3)$ & Andar rígido, tetania \\
\hline 15 & Canguçu & $07 / 2009$ & 2 anos & 38 & $15(39,47)$ & $15(39,47)$ & $\begin{array}{l}\text { Andar rígido, tetania, o- } \\
\text { pistótono e prolapso de } \\
3^{a} \text { pálpebra }\end{array}$ \\
\hline 16 & Dom Pedrito & $07 / 2009$ & 1,5 anos & 150 & $7(4,66)$ & $7(4,66)$ & Andar rígido, tetania \\
\hline 17 & Canguçu & $07 / 2009$ & 2 anos & 80 & $7(8,75)$ & $7(8,75)$ & $\begin{array}{l}\text { Andar rígido, opistótono } \\
\text { e quedas }\end{array}$ \\
\hline 18 & Uruguaiana & $08 / 2009$ & 1,5 anos & 700 & $8(1,14)$ & $8(1,14)$ & Andar rígido, tetania \\
\hline 19 & São Lourenço do Sul & $09 / 2009$ & 1,5 anos & 300 & $3(1,0)$ & $3(1,0)$ & Andar rígido, tetania \\
\hline 20 & Cristal & $09 / 2009$ & 2 anos & 2500 & $5(0,2)$ & $5(0,2)$ & Andar rígido, tetania \\
\hline 21 & São Lourenço do Sul & $09 / 2009$ & 1,5 anos & 251 & $5(1,99)$ & $5(1,99)$ & $\begin{array}{l}\text { Andar rígido opistótono } \\
\text { e quedas }\end{array}$ \\
\hline 22 & Canguçu & $10 / 2009$ & 8 meses & 65 & $3(4,61)$ & $3(4,61)$ & Andar rígido, tetania \\
\hline 23 & Canguçu & $12 / 2009$ & Adultos & 440 & $12(2,72)$ & $12(2,72)$ & Andar rígido, tetania \\
\hline 24 & Canguçu & $12 / 2009$ & 3 meses & 51 & $4(7,84)$ & $4(7,84)$ & Andar rígido, tetania \\
\hline TOTAL & & & & 15.126 & $249(1,64)$ & $244(1,61)$ & \\
\hline
\end{tabular}

tremores, trismo mandibular, andar com os membros rígidos, prolapso de terceira pálpebra e orelhas eretas. Com a evolução do quadro os bovinos permaneciam em decúbito lateral com opistótono, em alguns casos, com os membros esticados e afastados do solo (Fig.1A-D) e timpanismo leve a acentuado (Fig.1D).

Macroscopicamente os animais não apresentavam lesões em nenhum dos órgãos incluindo sistema nervoso central. Em 12 bovinos havia necrose muscular na musculatura do pescoço, onde havia sido realizada aplicação de medicamentos ou vacinas. Histologicamente não foram observadas lesões no sistema nervoso central e órgãos das cavidades torácica e abdominal.

Dos 24 camundongos não protegidos, inoculados com soro de animais doentes, provenientes de 12 surtos, seis manifestaram os sinais clínicos e cinco morreram. Dos 12 camundongos não protegidos inoculados com líquido seroso, associado às regiões de necrose muscular, dois morreram. Dos 12 camundongos não protegidos inoculados com o sobrenadante do meio de Robertson dois morreram. Os sinais clínicos iniciaram de 12 a 72 horas após a inoculação nos camundongos. Foi observada rigidez muscular, xifose, hiperexcitabilidade e morte.

Das colorações realizadas, a partir do exsudato seroso foi possível identificar em duas oportunidades Clostridium tetani.

Nenhum dos bovinos inoculados com os medicamentos e/ou vacinas recolhidos nas propriedades em que ocorre- ram surtos de tétano apresentaram sinais clínicos da doença.

\section{DISCUSSÃO}

O diagnóstico de tétano foi realizado pela epidemiologia e sinais clínicos associados aos resultados da inoculação em camundongos com material de lesões musculares e soro sanguíneo de bovinos afetados.

$\mathrm{Na}$ área de influência do LRD o tétano ocorre de forma esporádica com poucos casos isolados ou surtos com morbidade variável de $2,6 \%$ a 9,8\% (Schild et al. 2008). 0 grande número de surtos ocorridos no ano 2009 sugere que neste ano alguma condição epidemiológica específica tenha contribuído para a ocorrência da doença em um número expressivo de propriedades. Neste mesmo ano surtos de tétano ocorreram, também, na região Central do Estado (C.S.L. Barros 2009, comunicação pessoal) e no Litoral-Norte (D. Driemeier 2009, comunicação pessoal). Neste trabalho observou-se que em todos os surtos observados havia histórico de aplicação de algum medicamento ou vacinação nos animais em um período entre 8 e 25 dias antes do início dos sinais clínicos. No tétano o período de incubação pode variar de 8 horas a 4 semanas (Barros et al. 2006).

Tem sido mencionado que secas prolongadas favorecem a ocorrência de tétano. Nestes casos a contaminação da pele dos animais por poeira ou lama durante práticas de vacinação e vermifugação podem ser um meio de infecção 

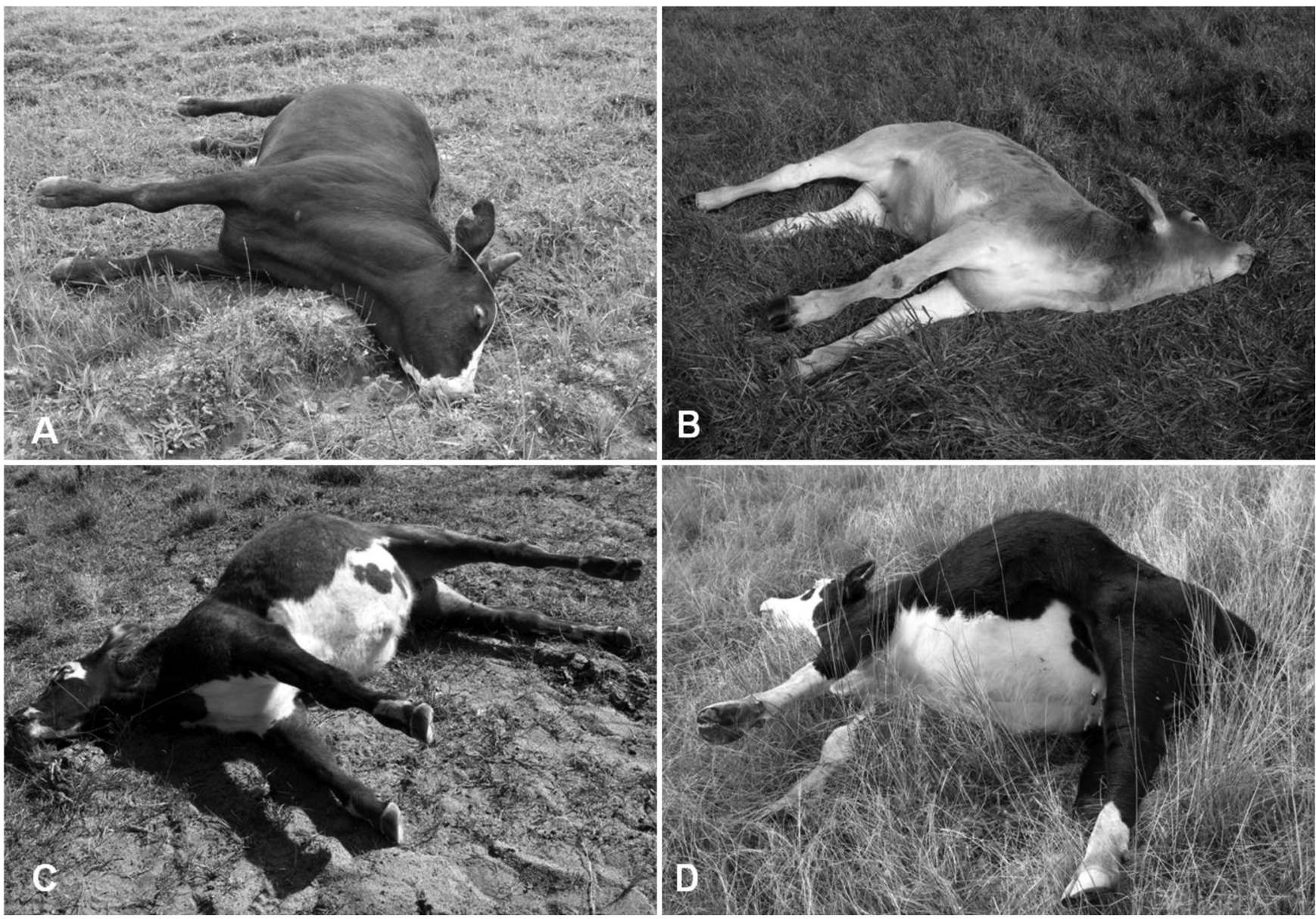

Fig.1. (A-D) Bovinos afetados nos diversos surtos de tétano diagnosticados em decúbito lateral com os membros esticados, afastados do solo, (B) com opistótono e (D) timpanismo acentuado.

(Dutra et al. 2001). Dos 24 surtos relatados neste trabalho, oito foram observados entre abril e maio quando havia estiagem na região. No entanto, a ocorrência de surtos após o período de estiagem parece sugerir que a seca pode ter contribuído porem não foi o único fator predisponente na alta prevalência do tétano durante o ano 2009.

Surtos de tétano já foram observados em bovinos alimentados com palha, tendo por porta de entrada a via digestiva em consequência de traumatismos provocados pelo alimento excessivamente fibroso (Raposo 2007, Barbosa et al. 2009). Restevas de lavouras ou pastos muito fibrosos podem ferir a mucosa oral dos animais possibilitando a penetração da bactéria (Barbosa et al. 2009). Campos com cobertura vegetal excessivamente rica em lignina devem ser periodicamente roçados para não predispor a estas lesões na mucosa oral dos animais. Em um estabelecimento no município de São Lourenço do Sul foi feito o diagnóstico de tétano em 19 novilhos de um total de 193, de um ano e meio de idade. Os animais adoeceram 15 dias após terem sido colocados em uma resteva de arroz recém colhido, evidenciando-se a possibilidade de que a infecção tenha ocorrido, provavelmente, por via digestiva em conseqüência de traumatismos causados pela palha de arroz (Riet-Correa et al. 1998).

Em 2001 diversos surtos de tétano ocorreram em bovinos e ovinos associados a aplicação de um único vermífugo
(Driemeier et al. 2007). Nos surtos de tétano observados em 2009 havia, também, alguns medicamentos ou vacinas idênticos utilizados nas diferentes propriedades e foi mencionada a aplicação dos mesmos nos bovinos entre 8 e 25 dias antes do início das manifestações clínicas da enfermidade. Isto poderia sugerir que neste ano a enfermidade teria sido causada, também, por contaminação de algum desses medicamentos ou vacinas. No entanto, os bovinos inoculados experimentalmente com estes medicamentos e vacinas não apresentaram sinais clínicos de tétano. De qualquer forma não pode descartar essa possibilidade, já que a ocorrência da doença está associada não só a contaminação de feridas pelo agente, mas também, às condições de anaerobiose que permitem a proliferação do agente e da quantidade de toxina produzida.

Os 24 surtos de tétano que ocorreram no ano 2009 têm características epidemiológicas semelhantes aos ocorridos no mesmo estado em 2001. Naquela oportunidade foi confirmada a contaminação de um anti-helmíntico utilizado nas propriedades onde ocorreram os surtos (Driemeier et al. 2007). Apesar de que o tétano aparentemente não é uma clostridiose importante em bovinos na área de influência do LRD, já que de 1978 a 2008 foram observados três surtos, mortalidades altas podem ocorrer em determinadas circunstâncias causando prejuízos econômicos importantes como os que ocorreram nos anos 2001 e 2009. 


\section{REFERÊNCIAS}

Barbosa J.D., Dutra M.D., Oliveira C.M.C., Silveira J.A.S., Albernaz T.T. \& Cerqueira V.D. 2009. [Outbreak of tetanus in bufalloes (Buballus bubalis) in Pará, Brazil.] Surto de tétano em búfalos (Buballus bubalis) no Estado do Pará. Pesq. Vet. Bras. 29(3):263-266.

Barros C.S.L., Driemeier D., Dutra I.S. \& Lemos R.A.A. 2006. Doenças do Sistema Nervoso de Bovinos no Brasil. AGNS Gráfica e Editora, São Paulo. $207 \mathrm{p}$.

Carter G.R., Chengappa M.M. \& Roberts A.W. 1995. Essentials of Veterinary Microbiology. $5^{\text {th }}$ ed. Williams and Wilkins, Baltimore, p.134-141.

Driemeier D., Schild A.L., Fernandes J.C., Colodel E.M., DCorrea A.M., Cruz C.E. \& Barros C.S.L. 2007. Outbreaks of tetanus in beef cattle and sheep in Brazil associated with disophenol injection. J. Vet. Med. A, Physiol. Pathol. Clin. Med. 54(6):333-353.

Dutra I.S., Ferreira R.M.M., Mingoti G.Z. \& Döbereiner J. 2001. Surto de tétano em bovinos de corte após aplicação de vermífugo e vacina. 8ํㅡㄴ gresso Brasileiro de Buiatria, Campo Grande, MS, p.46.

Lobato F.C.F. \& Assis A.R. 2005. Clostridioses dos animais. II Simpósio Mineiro de Buiatria, Belo Horizonte. (This manuscript is reproduced in the
IVIS website with the permission of Associação de Buiatria de Minas Gerais)

Lobato F.C.F., Salvarani F.M. \& Assis R.A. 2007. Clostridioses dos pequenos ruminantes. Revta Port. Ciênc. Vet. 102(561/562):23-34.

Raposo J.B. 2007. Tétano, p.425-432. In: Riet-Correa F., Schild A.L., Lemos R.A.A. \& Borges J.R.J. (Eds.), Doenças de Ruminantes e Eqüídeos. Vol.1. $3^{\underline{a}}$ ed. Pallotti, Santa Maria. $719 \mathrm{p}$.

Riet-Correa F., Schild A.L., Fernandes C.G. 1998. Enfermidades do sistema nervoso dos ruminantes no sul do Rio Grande do Sul. Ciência Rural 28(2):341-348.

Saraiva D. 1984. Clostridium tetani, p.363-376. In: Guerreiro G.M., Oliveira S.J., Saraiva D., Wiest J.M., Lieberknecht F., Poester F.P., Dias J.C.A., Fernandes J.C.T., Langeloh A. \& Baptista P.J.H.P. (Eds), Bacteriologia Especial: com interesse em saúde animal e saúde pública. Sulina, Porto Alegre. 492p.

Schild A.L., Ferreira J.L.M., Ladeira S.R.L., Ruas J.L. \& Soares M.P. 2008. Principais diagnósticos realizados no LRD em ruminantes, equinos e suínos entre 1978 e 2007. Boletim do Laboratório Regional de Diagnóstico, UFPel. Ed. Gráfica Universitária, Pelotas. pp.48-73.

Tortora G.J., Funke B.R. \& Case C.L. 2000. Microbiologia (Tradução). 6ํㅡㄹ. Editora Artmed, Porto Alegre, pp.584-585. 